\title{
DESIGNING MONETARY AND FISCAL POLICY RULES IN A NEW KEYNESIAN MODEL WITH RULE-OF-THUMB CONSUMERS
}

\author{
RAFFAele Rossi \\ University of Milano-Bicocca
}

This paper studies the determinacy properties of monetary and fiscal policy rules in a small-scale New Keynesian model. We modify the standard model in two ways. First, we allow positive public debt in the steady state as in Leeper [Journal of Monetary Economics 27, 129-147 (1991)]. Second, we add rule-of-thumb consumers as in Bilbiie [Journal of Economic Theory 140, 162-196 (2008)]. Leeper studied a model in which Ricardian equivalence holds, and he showed that monetary and fiscal policy can be studied independently. In Bilbiie's analysis, rule-of-thumb consumers break the Ricardian equivalence and generate important consequences for the design of monetary policy. In his model, steady-state public debt was equal to zero. We study a model with both rule-of-thumb consumers and positive steady-state public debt. We find that the mix of fiscal and monetary policies that guarantees equilibrium determinacy is sensitive to the exact values of the parameters of the model.

Keywords: Rule-of-thumb consumers, Ricardian equivalence, Public debt, Monetary-fiscal policy interactions

\section{INTRODUCTION}

When Ricardian equivalence holds, monetary and fiscal policy can be studied independently. For instance, in the logic presented in Leeper (1991), the joint design of monetary and fiscal policy reduces to two separable problems, which can be addressed recursively. When the monetary dynamics is determinate, local determinacy needs government debt dynamics to evolve passively in a stable manner. In contrast, if a system without fiscal policy exhibits one degree of indeterminacy, then potentially unstable debt dynamics is needed to restore equilibrium determinacy. This is consistent with Leeper's notion of active fiscal policy.

For helpful feedback and discussions, I am particularly grateful to two anonymous referees, Roger Farmer (the Associate Editor), Florin Bilbiie, Michela Cella, Andrea Colciago, Campbell Leith, Malcolm McColl, Ioana Moldovan, Giorgio Motta, Charles Nolan, Patrizio Tirelli, and Luca Stanca, and all the participants at the 4th European Macroeconomic Workshop and at the seminars of the economics departments of Glasgow and Milano-Bicocca Universities. Address correspondence for Raffaele Rossi, Department of Economics, University of Milano-Bicocca, Piazza dell'Ateneo Nuovo 1, 20126 Milan, Italy; e-mail: raffaele.rossi1@ unimib.it. 
However, the assumptions behind this approach are often questionable, and it has therefore been argued that its policy conclusions can be misleading. ${ }^{1}$ When for any reason Ricardian equivalence breaks down, monetary and fiscal policy cannot be studied separately.

Pursuing this theme further, this paper studies the stabilizing properties of monetary and fiscal policy in a small-scale New Keynesian model. ${ }^{2}$ We modify the standard framework in two ways. First, we allow a positive public debt in the steady state, as in Leeper (1991). Second, we introduce alongside traditional optimizing agents a share of rule-of-thumb consumers as in Bilbiie (2008). Ruleof-thumb consumers are excluded from participating in financial markets; i.e., they cannot hold public debt in order to smooth consumption over time, but simply consume their disposable labor income in each period. The main advantage of this modeling approach is that departures from Ricardian equivalence can be modeled conveniently through a change in a single parameter, which is the share of ruleof-thumb consumers present in the system. When this share is positive, both types of consumers pay the burden of public debt but only the optimizers benefit from it. Public debt becomes net wealth in the sense of Barro (1974) and consequently a relevant state variable that has to be taken into account for the equilibrium dynamics of the system.

Moreover, as stressed in the literature on limited asset market participation [Galí et al. (2004), Di Bartolomeo and Rossi (2007), Bilbiie (2008), Colciago (2011)], the introduction of a set of rule-of-thumb consumers can drastically change the determinacy conditions of an otherwise standard New Keynesian monetary model. As explained in Bilbiie (2008), these results stem from the implication that the consumption of rule-of-thumb consumers is sensitive to real wages, but not to interest rates. In turn, variations in real wages affect profits, thus impacting the consumption decisions of the optimizers. Higher interest rates depress wages, but raise profits enough to boost the demand of the optimizers. With a sufficiently large share of rule-of-thumb consumers, this boost is enough to offset the decline in demand from rule-of-thumb consumers, thus raising aggregate demand. In this case, determinacy may require passive monetary policy, whereby the central bank lowers the real interest rate in response to positive inflation.

We extend the results presented in Leeper (1991) and Bilbiie (2008) by studying the effects generated by the presence of rule-of-thumb consumers on the interactions between monetary and fiscal policy. First, when steady-state public debt is zero, monetary and fiscal policy making reduce to two separable problems, as in Leeper's work. We show that his logic extends to the case where the share of ruleof-thumb consumers is moderate. In contrast, when the share of rule-of-thumb consumers is large, equilibrium determinacy requires both monetary and fiscal policy to be active or both to be passive.

Second, when steady-state public debt is positive, monetary policy actions generate fiscal consequences. Furthermore, fiscal adjustments feed back onto the other endogenous variables of the model through wealth effects on aggregate demand that arise from the presence of rule-of-thumb consumers. For intermediate 
values of steady-state public debt and for both moderate and high values of the share of rule-of-thumb consumers, we find that the fiscal and monetary policies that ensure the determinacy of equilibrium are sensitive to the exact values of the parameters of the model.

This paper contributes to the literature in two ways. First, it extends the logic of Leeper (1991) in a non-Ricardian world. Therefore, our exercise can be seen as complementary to the work on the interaction between monetary and fiscal policy in New Keynesian models with non-Ricardian consumers à la Blanchard (1985), e.g., Leith and Wren-Lewis (2000) and Leith and von Thadden (2008). With this type of consumers, Ricardian equivalence fails because agents have a constant probability of death. Hence, as in the model proposed here, public debt produces wealth effects and has to be taken into account in the determinacy analysis. Similarly, our paper relates to models where Ricardian equivalence fails because of the presence of income taxation and steady-state public debt, as in Linnemann (2006) and Schmitt-Grohé and Uribe (2007).

Second, it extends the logic spelled out by Bilbiie (2008) on the fiscal policy side. Our exercise contributes to the literature that studies the consequences for equilibrium determinacy of introducing rule-of-thumb consumers in a sticky price environment, e.g., Galì et al. (2004), Di Bartolomeo and Rossi (2007), Motta and Tirelli (2010), Colciago (2011) and Ascari et al. (2011). However, the cited literature concentrates exclusively on the monetary policy effects of rule-of-thumb consumers. A key difference of our study is that we instead focus on the consequences of introducing rule-of-thumb consumers for interaction between monetary and fiscal policy.

The remainder of the paper is structured as follows: Section 2 outlines the model, Section 3 discusses the main results of the paper, and Section 4 concludes.

\section{MODEL}

The economy consists of two types of households, a continuum of firms producing differentiated goods in a monopolistic competitive-sticky price environment, a perfectly competitive labor market, a central bank in charge of monetary policy, and a government in charge of fiscal policy.

The totality of households is normalized to unity. Of this, a fraction $(1-\lambda)$, with $\lambda \leq 1$, behaves in a traditional forward-looking, optimizing way. Hence, this fraction maximizes lifetime utility, holds profits coming from the monopolistic nature of the goods market, and participates in perfect and complete financial markets. We define the remaining $\lambda$ households as rule-of-thumb consumers (henceforth ROTC) as in Galí et al. (2004, 2007) and Bilbiie (2008). For these consumers, all their wealth is represented by their after-tax wage and therefore they cannot smooth consumption over time. Variables with the suffixes " $o$ " and " $r$ " indicate optimizers and ROTC, respectively. A variable without a time index identifies its steady state value. 


\subsection{Optimizers}

The optimizers' utility function has a standard form and simply includes consumption and labor,

$$
U_{t}^{o}=E_{t} \sum_{t=0}^{+\infty} \beta^{t}\left[\log C_{t}^{o}-\chi \frac{\left(N_{t}^{o}\right)^{1+\eta}}{1+\eta}\right],
$$

where $E_{t}$ is the rational expectations operator, $\beta \in(0,1)$ is the discount factor, $C_{t}^{o}$ is the level of consumption of the optimizers, and $N_{t}^{o}$ is the optimizers' labor supply. The parameter $\chi$, with $\chi \in(0, \infty)$, indicates how leisure is valued relative to consumption. The parameter $\eta>0$ is the inverse of the Frisch elasticity of labor supply.

The optimizers' nominal flow budget constraint is

$$
\begin{gathered}
\int_{0}^{1} P_{t}(j) C_{t}^{o}(j) d j+R_{t}^{-1} \frac{B_{t+1}}{1-\lambda}+\frac{E_{t}\left(Q_{t, t+1} V_{t+1}\right)}{1-\lambda} \\
=W_{t} N_{t}^{o}+\frac{\Pi_{t}}{1-\lambda}+\frac{B_{t}}{1-\lambda}+\frac{V_{t}}{1-\lambda}-P_{t} \tau_{t}-P_{t} S^{o},
\end{gathered}
$$

where $P_{t}(j)$ is the price level of the variety of $\operatorname{good} j, W_{t}$ is the nominal wage, $\Pi_{t}$ are the nominal profits coming from the monopolistic competitive firms, $B_{t+1}$ is the nominal payoff of the one-period riskless bond purchased at time $t, R_{t}$ is the gross nominal return on bonds purchased in period $t, Q_{t, t+1}$ is the stochastic discount factor for one-period-ahead payoff, $P_{t}$ is the aggregate price level, and $V_{t}$ is the nominal payoff of a state-contingent asset portfolio. ${ }^{3}$ The government is assumed to service the public debt by levying a lump-sum tax, $\tau_{t}$. We define $S^{o}$ as a transfer such that at steady state the two types of agents have the same level of consumption and supply the same amount of labor. ${ }^{4}$

Optimizers first decide how to allocate a given level of expenditure across different goods. Optimal behavior implies a standard demand function for any good $j$ as

$$
C_{t}^{o}(j)=\left[\frac{P_{t}(j)}{P_{t}}\right]^{-\varepsilon} C_{t}^{o} \text { and } \int_{0}^{1} P_{t}(j) C_{t}^{o}(j) d j=P_{t} C_{t}^{o},
$$

where the parameter $\varepsilon$ represents the elasticity of substitution among goods. The other first-order conditions yield to the Euler equation

$$
\beta R_{t} E_{t}\left[\left(\frac{C_{t}^{o}}{C_{t+1}^{o}}\right)\left(\frac{P_{t}}{P_{t+1}}\right)\right]=1,
$$

where $R_{t}=1 / E_{t}\left(Q_{t, t+1}\right)$ is implied by the nonarbitrage condition, and to the optimal labor supply

$$
\chi\left(N_{t}^{o}\right)^{\eta} C_{t}^{o}=\frac{W_{t}}{P_{t}} .
$$




\subsection{Rule-of-thumb consumers}

The utility function of ROTC is represented by a single-period expression. In particular, following Galí et al. (2004, 2007), it is assumed that the shape of the instantaneous utility is the same for the two types of agents. Therefore

$$
U_{t}^{r}=\log C_{t}^{r}-\chi \frac{\left(N_{t}^{r}\right)^{1+\eta}}{1+\eta}
$$

As stressed earlier, ROTC do not participate in financial markets and do not hold profits. Their budget constraint can be expressed as follows:

$$
\int_{0}^{1} P_{t}(j) C_{t}^{r}(j) d j=W_{t} N_{t}^{r}-P_{t} \tau_{t}-P_{t} S^{r},
$$

where $C_{t}^{r}(j)$ and $N_{t}^{r}$ are the level of consumption of each $j$ product and the labor supply of ROTC. On the consumption side, ROTC are forced to consume all their income in each period; therefore, consumption can easily be inferred from (7). The first-order condition for the labor supply is

$$
\chi\left(N_{t}^{r}\right)^{\eta} C_{t}^{r}=\frac{W_{t}}{P_{t}}
$$

\subsection{Firms}

The firms' problem is standard and therefore this subsection can be skipped by some readers without loss of continuity.

In this economy, firms are assumed to possess an identical linear production technology of the type

$$
Y_{t}(j)=N_{t}(j)
$$

and to face the demand function

$$
Y_{t}(j)=\left[\frac{P_{t}(j)}{P_{t}}\right]^{-\varepsilon} Y_{t}
$$

Following the New Keynesian literature, we assume sticky prices à la Calvo (1983). In each period there is a (randomly selected) set of firms, $(1-\theta)$ with $\theta<1$, that reset their prices optimally, whereas the remaining $\theta$ keep their prices fixed. When a firm is allowed to reset its prices, it takes into account the expected future stream of profits discounted for the probability of not resetting its prices. More precisely, the maximization problem of a price setter can be written in real terms as

$$
\max _{P_{t}^{*}(j)} E_{t} \sum_{i=0}^{+\infty} \theta^{i} q_{t, t+i}\left\{\left[\frac{P_{t}^{*}(j)}{P_{t+i}}\right] Y_{t+i}(j)-\mathrm{mc}_{t+i} Y_{t+i}(j)\right\}
$$


where $q_{t, t+1}=\beta\left(C_{t}^{o} / C_{t+1}^{o}\right)$ is the real stochastic discount factor and $\mathrm{mc}_{t}=W_{t} / P_{t}$ represents real marginal costs. The first-order condition with respect to $P_{t}^{*}(j)$ and the aggregate price level are

$$
\frac{P_{t}^{*}(j)}{P_{t}}=\left(\frac{\varepsilon}{\varepsilon-1}\right) \frac{E_{t} \sum_{i=0}^{+\infty} \theta^{i} \beta^{i}\left(\frac{C_{t}^{o}}{C_{t+i}^{o}}\right)\left(\mathrm{mc}_{t+i}\left(P_{t+i}\right)^{\varepsilon} Y_{t+i}\right)}{E_{t} \sum_{i=0}^{+\infty} \theta^{i} \beta^{i}\left(\frac{C_{t}^{o}}{C_{t+i}^{o}}\right)\left(P_{t+i}\right)^{\varepsilon} P_{t+i}^{-1} Y_{t+i}}
$$

and

$$
P_{t}^{(1-\varepsilon)}=\left[(1-\theta) P_{t}^{*(1-\varepsilon)}+\theta P_{t-1}^{(1-\varepsilon)}\right] .
$$

\subsection{Aggregation rules and market-clearing condition}

The aggregate expressions for consumption and labor are simply the weighted averages of the single consumer-type variables. Therefore, aggregate consumption is

$$
C_{t}=\lambda C_{t}^{r}+(1-\lambda) C_{t}^{o}
$$

and aggregate labor follows

$$
N_{t}=\lambda N_{t}^{r}+(1-\lambda) N_{t}^{o} .
$$

Without capital accumulation, everything produced must be consumed in the same period. Hence,

$$
Y_{t}(j)=C_{t}(j) .
$$

The aggregate production is

$$
Y_{t} s_{t}=N_{t},
$$

where $s_{t}=\int_{0}^{1}\left(\frac{P_{t}(j)}{P_{t}}\right)^{-\varepsilon} d j$ is a measure of aggregate price dispersion and $Y_{t}=$ $\int_{0}^{1} Y_{t}(j) d j$. Given our assumption of zero steady state inflation, fluctuations of $s_{t}$ around the steady state are of second-order importance, ${ }^{5}$ and therefore can be ignored in the present analysis, which employs a first-order approximation. At equilibrium, total demand is equal to total supply. Hence, defining $C_{t}=$ $\int_{0}^{1} C_{t}(j) d j$, we get

$$
Y_{t}=C_{t}
$$

\subsection{Monetary policy}

Monetary policy sets the nominal interest rate, $R_{t}$, in every period. In line with the literature on New Keynesian monetary policy, e.g., Bernanke and Woodford (1998), Clarida et al. (2000), Woodford (2003, Chap. 4), Carlstrom and Fuerst (2005), and Bilbiie (2008), we approximate monetary policy by a simple forwardlooking Taylor rule of the type

$$
R_{t}=R\left(E_{t} \pi_{t+1}\right)^{\phi},
$$


where $R=1 / \beta$ is the steady state interest rate and $\pi_{t}=P_{t} / P_{t-1}$ represents the inflation rate. The single policy parameter $\phi$ in (19) is the Taylor coefficient, as discussed in the literature on interest rate rules inspired by Taylor (1993). ${ }^{6}$

Accordingly, following Leeper (1991), monetary policy is called active (passive) if the nominal interest rate, $R_{t}$, rises more (less) than one for one with the expected inflation rate, i.e., if $\phi>1(\phi<1)$.

\subsection{Government and fiscal policy}

The government uses lump-sum taxes, $\tau_{t}$, to service the public debt. The government budget constraint can be expressed in real terms as

$$
R_{t}^{-1} b_{t+1}=\pi_{t}^{-1} b_{t}-\tau_{t}
$$

where $b_{t+1}=B_{t+1} / P_{t}$.

Furthermore, we assume that fiscal policy follows a rule of the type

$$
\tau_{t}=(1-\beta) b+\delta\left(b_{t}-b\right)
$$

where $\delta$ is a policy parameter identifying how taxation responds to government debt.

Unlike monetary policy, there is no widely accepted specification for fiscal policy. The rule adopted here is similar to the one considered in Davig and Leeper (2006), Linnemann (2006), and Leith and von Thadden (2008). Although the structure of the fiscal rule is basic, it nevertheless allows the study of the interactions between monetary and fiscal policy using the logic of Leeper (1991).

\subsection{Equilibrium}

The nonlinear structural equations of the model are log-linearized around the nonstochastic steady state. We present the model in terms of aggregate variables. A variable with a circumflex identifies $\log$ deviation from its steady state value; e.g., $\hat{C}_{t}=\log \left(C_{t} / C\right)$. Furthermore, we define $\widetilde{\tau}_{t}=\frac{\tau_{t}-\tau}{Y}$ and $\widetilde{b}_{t}=\frac{b_{t}-b}{Y}$.

The equations of the model are

(i) the New Keynesian Phillips curve,

$$
\hat{\pi}_{t}=\beta E_{t} \hat{\pi}_{t+1}+\sigma \hat{Y}_{t}
$$

(ii) the dynamic IS curve augmented for the presence of ROTC,

$$
\hat{Y}_{t}=E_{t} \hat{Y}_{t+1}-\Theta\left(\hat{R}_{t}-E_{t} \hat{\pi}_{t+1}\right)+\Theta \Gamma\left(E_{t} \widetilde{\tau}_{t+1}-\widetilde{\tau}_{t}\right)
$$

(iii) the government budget constraint,

$$
\beta\left(\widetilde{b}_{t+1}-\gamma \hat{R}_{t}\right)+\widetilde{\tau}_{t}=\left(\widetilde{b}_{t}-\gamma \hat{\pi}_{t}\right)
$$

(iv) the monetary rule,

$$
\hat{R}_{t}=\phi E_{t} \hat{\pi}_{t+1}
$$


(v) the fiscal policy rule,

$$
\widetilde{\tau}_{t}=\delta \widetilde{b}_{t}
$$

where

$$
\begin{aligned}
\kappa & =\frac{(1-\theta)(1-\theta \beta)}{\theta} \\
\sigma & =(1+\eta) \kappa, \Theta=(1-\lambda)\left[1-\lambda \frac{\left(\frac{\eta \varepsilon-\eta}{\eta \varepsilon+\varepsilon-1}\right)(1+\eta)^{2}}{\eta}\right]^{-1}, \\
\Gamma & =\left[\frac{\varepsilon}{\varepsilon-1} \frac{\lambda}{1-\lambda}\left(\frac{\eta \varepsilon-\eta}{\eta \varepsilon+\varepsilon-1}\right)\right]
\end{aligned}
$$

and $\gamma=B / Y$ identifies the steady state debt-to-output ratio. ${ }^{7}$

A few points are worth stressing. First, the presence of ROTC dramatically affects the dynamic IS equation (23), i.e., the demand side of the economy, via $\Theta$. This parameter identifies the elasticity of aggregate demand to real interest rates and taxes. It is linked in a nonlinear way to $\lambda$, the share of ROTC, and to $\eta$, the inverse of the Frisch elasticity of labor. Both the size and the sign of $\Theta$ can drastically alter the transmission mechanism and local determinacy properties of the model. For example, an interest rate change modifies the intertemporal consumption and labor supply decisions of the optimizers. This affects aggregate demand, real wages, and consequently the consumption of ROTC, who simply consume their disposable labor income. At the same time, movements in real wages - and hence in marginal costs - cause variations in profits that are held exclusively by the optimizers. Similarly, changes in the real interest rate modify the return of public debt assets possessed by the optimizers. These financial effects work in the opposite direction relative to the traditional intertemporal Euler equation logic: whereas the latter implies a contractionary effect of higher real interest rate, the former has the opposite effect. ${ }^{8}$

As argued by Bilbiie and Straub (2004) and Bilbiie (2008), the sign of $\Theta$ determines which of these two channels prevails. As is known, the sign of $\Theta$ depends both on the share of ROTC - i.e., the higher the value of $\lambda$, the stronger the financial effects of interest rate movements - and on the elasticity of labor supply-i.e. the higher $\eta$, the higher the sensitivity of real wage to interest rate.

A necessary condition for $\Theta>0$ is

$$
\lambda<\lambda^{*}=\frac{\eta}{\left(\frac{\eta \varepsilon-\eta}{\eta \varepsilon+\varepsilon-1}\right)(1+\eta)^{2}} .
$$

Figure 1 sketches the sign of $\Theta$ in the $(\lambda-\eta)$ space. As can be seen, $\Theta$ remains positive for combinations of high values of the Frisch elasticity of labor supply, i.e., low $\eta$, and high shares of ROTC, i.e., high $\lambda$, or vice versa. ${ }^{9}$ 


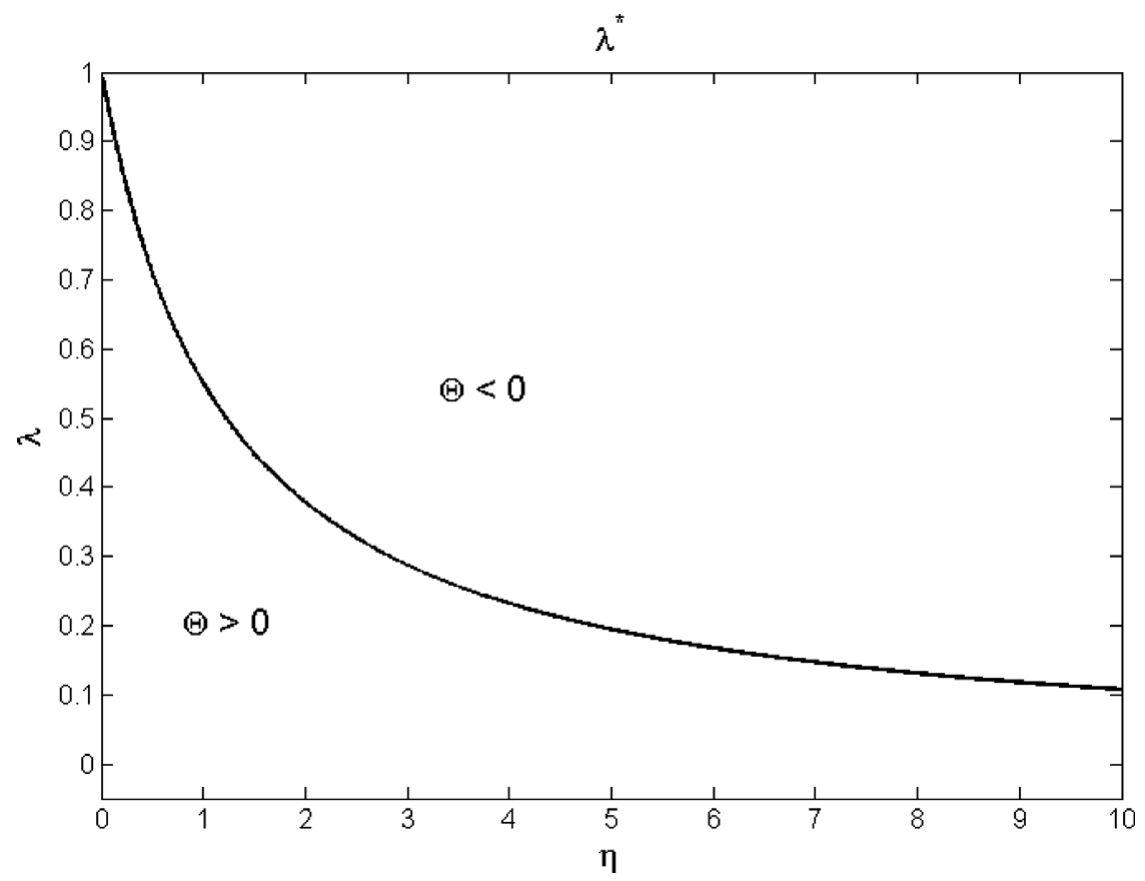

FIGURE 1. Signs of $\Theta$ and $\lambda^{*}$ in the $\lambda-\eta$ space. Below the line, $\Theta>0$. Above the line, $\Theta<0$.

Furthermore, it should be noted that, in the range of parameter values where $\Theta$ is positive, an increase in ROTC share increases the sensitivity of aggregate demand to interest rate movements; i.e. increasing the interest rate affects real wages negatively. This implies lower consumption for ROTC. At the same time, a higher interest rate has a traditional effect on optimizers' consumption. In contrast, when $\lambda>\lambda^{*}$, as $\lambda$ tends to its upper limit $1, \Theta$ decreases (in absolute value) asymptotically toward zero. In other words, interest rate policies are ineffective when no one holds assets.

The immediate consequence of these effects generated by the presence of ROTC is that an economy that displays a negative $\Theta$ requires a passive monetary policy rule for determinacy.

Second, both types of consumers pay the burden of public debt, but only the optimizers benefit from it. Hence, public debt is net wealth in the sense of Barro (1974), Ricardian equivalence does not hold, and equilibrium dynamics is driven by a genuine interaction between monetary and fiscal policy.

The main focus and contribution of the present study are the consequences of these interactions for the joint design of monetary and fiscal policy rules. 


\section{RESULTS}

\subsection{Parameterization}

The model is calibrated to a quarterly frequency. ${ }^{10}$ We assume the elasticity of substitution among goods, $\varepsilon$, to be equal to 6 . This implies a steady-state markup of $20 \%$, which is in line with the majority of the macro literature. The discount factor $\beta$ has been fixed at 0.99 , so that the real annual interest rate is $4 \%$. As in most of the New Keynesian literature, we assume that prices remain unchanged on the average for one year. Therefore, $\theta$ is fixed at 0.75 . These parameters are kept at baseline values throughout the following examples. We then turn to the parameters for which some sensitivity analysis is conducted, by examining a range of values in addition to their baseline settings. The model is solved with several pairs of $\lambda$, the share of ROTC, and $\eta$, the inverse Frisch elasticity of labor supply, depending on whether the aim is to study a situation where $\Theta$ is positive or negative. ${ }^{11}$

Further, we solve the model with various levels of debt-to-GDP ratios, 0\%, $60 \%$, and $80 \%$. Similarly, in order to describe the active-passive policy mix, the determinacy conditions are analyzed for a broad range of monetary and fiscal policy parameters. ${ }^{12}$

\subsection{Determinacy}

The determinacy of the model follows from Propositions 1 and 2.

Assumption 1. For $\Theta>0$ assumes that $\gamma<1 / \Gamma \sigma$.

The restriction on the steady state level of public debt is innocuous. For standard parameter values, Assumption 1 implies an upper limit on public debt far above $400 \%$ of total output.

PROPOSITION 1. Let $\Theta>0, \quad \bar{\phi}=\frac{2(1+\beta)+\Theta \sigma-2 \gamma \Gamma \Theta \sigma}{\Theta \sigma+2 \beta \gamma \Gamma \Theta \sigma}, \bar{\delta}=$ $\frac{(1+\beta)[2(1+\beta)+\Theta \sigma(1-\phi)]}{\Theta \sigma(1-\phi-2 \gamma \Gamma)+2[1+\beta(1-\gamma \Gamma \Theta \sigma \phi)]}$, Assumption 1 hold, and $\phi \in[0,+\infty)$. The necessary and sufficient condition for the determinacy of the dynamic system defined by (22)-(26) is

$$
\begin{aligned}
& {[\phi \in(1, \bar{\phi}) \cap \delta \in(1-\beta, \bar{\delta})]} \\
& \cup[\phi \notin(1, \bar{\phi}) \cap \delta \notin(1-\beta, \bar{\delta})] .
\end{aligned}
$$

Furthermore, $\bar{\delta}$ is bounded below by $(1+\beta)$, increasing in the share of ROTC, i.e., $\partial \bar{\delta} / \partial \lambda>0$, increasing in the level of steady-state public debt, i.e., $\partial \bar{\delta} / \partial \gamma>0$ and increasing in the monetary policy parameter, i.e., $\partial \bar{\delta} / \partial \phi>0$.

Proof. See Appendix B.

COROLLARY 1. If $\lambda$ and/or $\gamma$ equal zero, then $\bar{\phi}=1+2 \frac{(1+\beta)}{\Theta \sigma}$ and $\bar{\delta}=1+\beta$.

Corollary 1 underlines that Proposition 1 perfectly nests Leeper's logic when there is no steady state public debt and/or ROTC are not present in the system. 
When this is the case, public debt dynamics is completely uncoupled from the rest of the model. Therefore monetary and fiscal policy can be studied as two independent problems. For example, when fiscal policy acts in such a way that government debt dynamics evolves passively in a stable manner, i.e., $\delta \in(1-$ $\beta, 1+\beta$ ), equilibrium determinacy is guaranteed by an active monetary policy, which, following the Taylor principle, ${ }^{13}$ anchors inflation expectations. However, if the Taylor principle is abandoned, so that a passive monetary policy fails to control inflation expectations, then determinacy needs fiscal policy to be set in an active way so that debt dynamics is potentially unstable; i.e., $\delta \notin(1-\beta, 1+\beta)$.

When steady-state public debt is nonzero and, ceteris paribus, the share of ROTC is positive, the government budget constraint is no longer uncoupled from the rest of the model. Movements in nominal interest rate and current inflation feedback on public debt, which in turn feeds back on the rest of the model via the demand side of the economy.

Here, there are a few points worth stressing. First, the fiscal parameter limit, upper or lower depending on whether monetary policy is active or passive, i.e., $\bar{\delta}$, is bounded below by $(1+\beta)$ and is increasing in the share of ROTC, in the steady state level of public debt, and in the monetary policy parameter.

At a microeconomic level, the intuition for this can be explained as follows. Assume that monetary policy follows the Taylor principle, i.e., $\phi>1$, so that the nominal rate increases more than expected inflation, and suppose that a positive, nonfundamental shock hits agents' inflation expectations. The increase in the real interest rate leads to a decrease in the consumption of the optimizers, and hence a decrease in the demand for goods. This causes downward pressure on real wages and consequently an additional reduction of consumption of ROTC. Moreover, nominal price rigidities imply that lower demand induces some firms to lower their prices and others to decrease labor demand. This, in turn, implies a further decrease in the equilibrium real wage. On the other hand, a higher real interest rate causes an increase in the burden of public debt and, via the fiscal rule, an increase in taxation. The distortive nature of fiscal policy implies that each rise in taxation leads to a reduction in ROTC consumption. This reduction mechanism causes another decrease in the equilibrium real wage (and marginal cost). These fiscal effects, obtained by the combined presence of ROTC and steady state public debt, put further downward pressure on current and expected inflation, thus invalidating the initial increase in expectations. As a result there is a weaker response (than a Ricardian scenario) during the transition path of interest rate, public debt, and taxation. In other words, the presence of a share of ROTC allows fiscal policy to induce a stationary path of public debt even when $\delta \in[(1+\beta), \bar{\delta}]$.

Moreover, the mechanism described is stronger (i) the higher the share of ROTC, i.e., high presence of credit-constrained agents increases the distortive effects of fiscal policy; (ii) the higher the steady state level of public debt, i.e., high steady state public debt increases monetary feed-back on the government budget constraint, in turn amplifying the effects of fiscal policy; and (iii) the stronger the monetary policy reaction to inflation expectations, i.e., strong reactions to inflation 

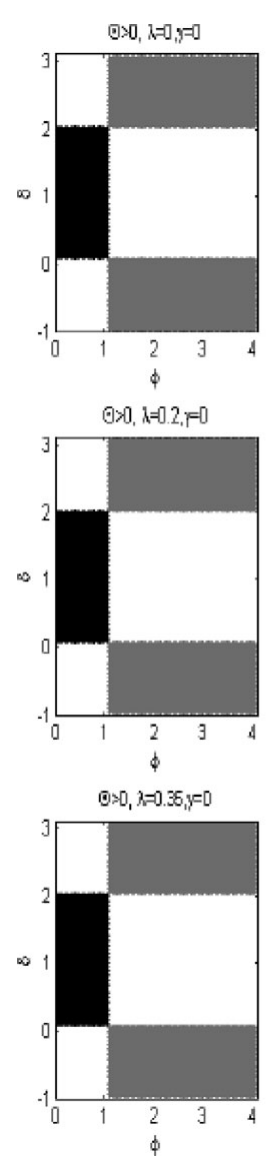
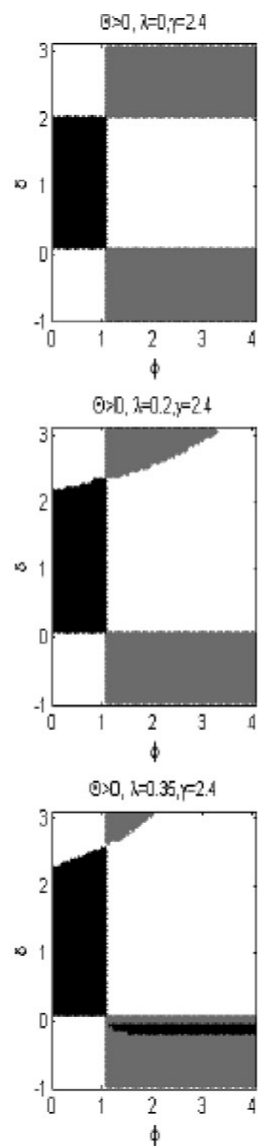
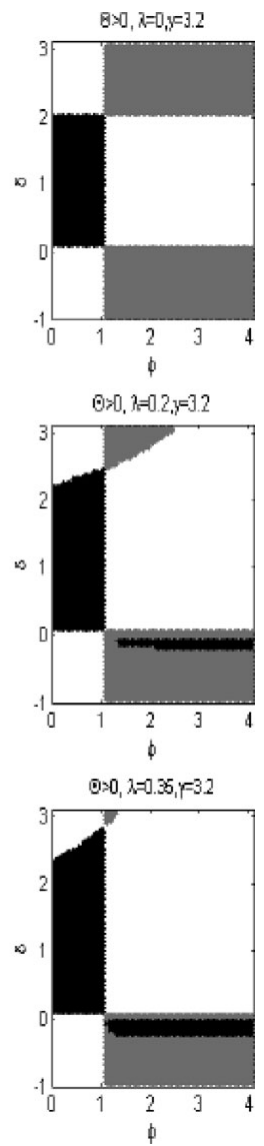

FIGURE 2. Determinacy analysis with positive $\Theta$. Determinacy (white areas), indeterminacy (black areas), and instability (red areas).

expectations, all else being equal, increase the wealth effects of fiscal policy on aggregate demand.

Similarly, when monetary policy is passive, i.e., $\phi<1$, it may fail to threaten to put the economy on an explosive-inflation path for any deviation from the unique rational-expectations equilibrium. In this case, equilibrium determinacy requires setting fiscal policy in an active way so that debt dynamics are potentially unstable. To do so, fiscal policy needs to be more aggressive against public debt compared to a scenario where steady state public debt equals zero or only optimizer agents exist, i.e., $\delta>\bar{\delta}$.

Figure 2 graphically illustrates the determinacy results. The numerical values are taken from the benchmark parameterization, as described in Section 3.1. Each subplot details the combinations of the monetary policy parameter and the fiscal policy parameter which ensure determinacy (blanks), indeterminacy 
(black spots), and instability (red spots). Moving from left to right across subplots increases the level of steady state public debt, whereas moving down the page increases the extent of ROTC. Consistent with the previously described economic mechanism, the higher the share of ROTC, the steady state level of public debt, or the monetary policy parameter, the great the possibility that fiscal policy reactions greater than $1+\beta$ generate determinacy (indeterminacy) when monetary policy is active (passive). For example, with $35 \%$ of ROTC, $\eta=1$, a steady state public debt-to-output ratio of $60 \%$, and a monetary policy parameter of $1.2, \bar{\delta}=2.74$, whereas if $\phi=0.8, \eta=1$, and $\gamma=2.4, \bar{\delta}=2.35$.

Next, we analyze the equilibrium dynamics when $\Theta$ turns negative.

Assumption 2. For $\Theta<0$, assume that $\Theta \leq \frac{-2+2 \beta}{2 \gamma \sigma+\sigma \phi+2 \gamma \sigma \phi}$.

Assumption 2 implies an upper bound on the share of ROTC well above available estimates. ${ }^{14}$ Although this assumption keeps the algebra simple, it is neutral in relation to the present analysis.

PROPOSITION 2. Let $\Theta<0, \quad \bar{\phi}=\frac{2(1+\beta)+\Theta \sigma-2 \gamma \Gamma \Theta \sigma}{\Theta \sigma+2 \beta \gamma \Gamma \Theta \sigma}, \bar{\delta}=$ $\frac{(1+\beta)[2(1+\beta)+\Theta \sigma(1-\phi)]}{\Theta \sigma(1-\phi-2 \gamma \Gamma)+2[1+\beta(1-\gamma \Gamma \Theta \sigma \phi)]}$, Assumption 2 hold, and $\phi \in[0,+\infty)$. The necessary and sufficient condition for the determinacy of the dynamic system defined by (22)-(26) is

$$
\begin{aligned}
& {[\phi \in(\max (\bar{\phi}, 0), 1) \cap \delta \in(1-\beta, \bar{\delta})]} \\
& \cup[\phi>1 \cap \delta \notin(1-\delta, \bar{\delta})]
\end{aligned}
$$

Furthermore, $\bar{\delta}$ is bounded above by $(1+\beta)$, increasing in the share of ROTC, i.e., $\partial \bar{\delta} / \partial \lambda>0$, decreasing in the steady-state public debt, i.e., $\partial \bar{\delta} / \partial \gamma<0$, and decreasing in the monetary policy parameter, i.e., $\partial \bar{\delta} / \partial \phi<0$.

Proof. See Appendix B.

COROLLARY 2. If $\gamma$ equals zero, then $\bar{\phi}=1+2 \frac{(1+\beta)}{\Theta \sigma}$ and $\bar{\delta}=1+\beta$.

Corollary 2 shows that when $\Theta<0$ and $\gamma=0$, determinacy properties perfectly nest within the logic of Leeper (1991) and of Bilbiie (2008). As discussed, in this case, when fiscal policy acts in such a way that government debt dynamics evolves passively in a stable manner, i.e., $\delta \in(1-\beta, 1+\beta)$, monetary policy, in order to anchor expectations, needs to abandon the Taylor principle, as in Bilbiie and Straub (2004) and Bilbiie (2008). However, if the system without fiscal policy exhibits one degree of indeterminacy, then equilibrium determinacy requires setting fiscal policy in an active way so that debt dynamics is potentially unstable; i.e., $\delta \notin(1-\beta, 1+\beta)$. This stops being true as steady state public debt turns positive.

There are a few further points worthy of comment. First, the fiscal parameter limit, lower or upper depending on whether monetary policy is active or passive, i.e., $\bar{\delta}$, is bounded above by $(1+\beta)$ and is decreasing in the steady state level of 
public debt and in the monetary policy parameter and is increasing in the share of ROTC.

The intuition for this is as follows. As before, assume that agents suddenly expect higher inflation and monetary policy follows the Taylor principle. As $\gamma$ turns positive, a higher interest rate feeds back on the government budget constraint, putting upward pressure on public debt and, via the fiscal rule, on taxes. As before, higher taxes and a higher interest rate depress ROTC demand and put downward pressure on real wages, and hence on marginal costs. Lower marginal costs generate an increase in profits. When $\Theta<0$, the positive wealth effect generated by a higher return on public debt assets and higher profits feeds back into the system via the optimizers' budget constraint, inducing a boost in aggregate demand. This boost causes a further increase in the real interest rate and an additional rise in public debt and taxation. As a result, along the transition path, there is a stronger response (compared to a scenario with no steady state public debt) of interest rate, public debt, and taxation. In other words, when $\Theta<0$ and $\gamma>0$, fiscal policy may imply a potentially nonstationary path of public debt for $\delta \in[\bar{\delta},(1+\beta)]$. This, combined with a monetary policy that, following the Taylor principle, can potentially induce unstable monetary dynamics, generates determinacy.

Moreover, (i) these effects increase in the monetary policy parameter $\phi$; i.e., the higher the interest rate the stronger the boost to the financial wealth of the optimizers. This generates an increase in aggregate demand, in the real interest rate, and in public debt. (ii) They also increase in the steady state level of public debt; i.e., the higher the steady state public debt, the stronger the fiscal wealth effects. (iii) They decrease in the share of ROTC; i.e., when $\Theta<0$, $\Theta$ decreases (in absolute value) in $\lambda$ and this mitigates the joint monetary and fiscal transmission mechanism.

Ceteris paribus, when monetary policy manages, via a passive rule, to anchor inflation expectations, i.e., $\phi<1$, equilibrium determinacy requires that public debt evolve in a stable manner. This in turn imposes an upper limit on the conduct of fiscal policy such that $\delta \in(1-\beta, \bar{\delta})$.

Figure 3 repeats the graphical explanation for the case $\Theta<0$. As discussed, $\bar{\delta}$ is smaller than $1+\beta$, i.e., 1.99, decreasing in $\gamma$ and in $\phi$, and increasing in $\lambda$. For example, when $\lambda=0.35, \eta=4, \gamma=2.4$, and $\phi=1.2$ then $\bar{\delta}=1.13$. All else being equal, if $\gamma=3.2$ then $\bar{\delta}=1$ and if $\phi=0.8$ then $\bar{\delta}=1.25$. Last, if $\lambda=0.45, \eta=3, \gamma=2.4$, and $\phi=1.2$ then $\bar{\delta}=1.21$.

\section{CONCLUSIONS}

This paper studies the interactions between monetary and fiscal policy in a smallscale New Keynesian model. We add to the standard setting a positive level of steady state public debt as in Leeper (1991) and a share of rule-of-thumb consumers (ROTC) as in Bilbiie (2008). With these consumers, who do not hold profits and who are not allowed to engage in financial activities, public debt 

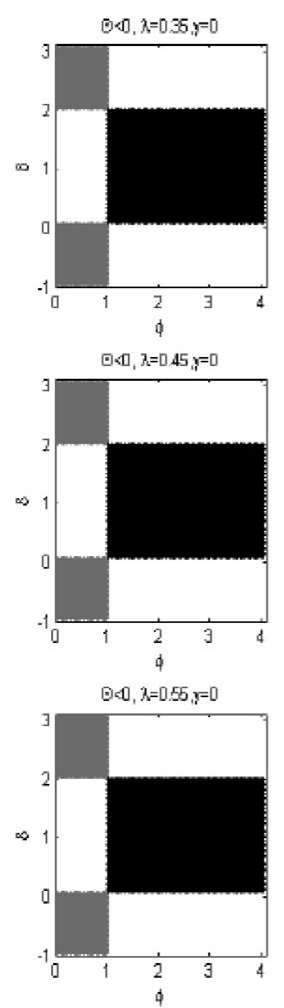
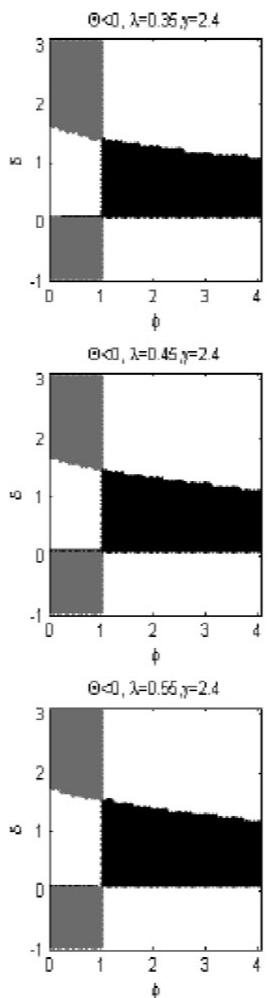
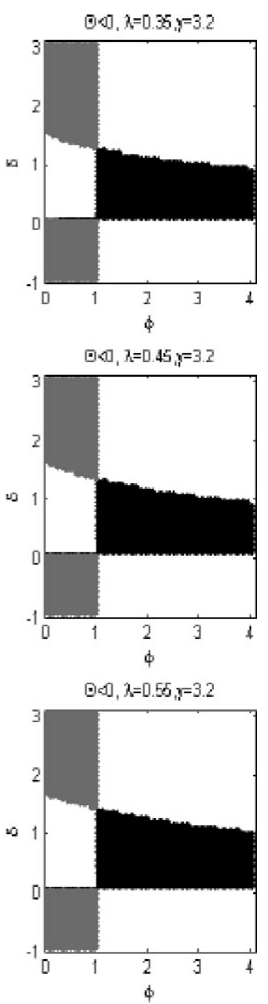

FIGURE 3. Determinacy analysis with negative $\Theta$. Determinacy (white areas), indeterminacy (black areas), and instability (red areas).

becomes net wealth in the sense of Barro (1974) even when all taxation is lumpsum. Hence, Ricardian equivalence breaks down. Furthermore, as discussed in Bilbiie and Straub (2004), Galì et al. (2004), and Bilbiie (2008), the introduction of a set of ROTC into an otherwise standard New Keynesian model has dramatic consequences for the conduct of interest rate policies.

With this in mind, this paper analyzes the stabilizing properties of simple monetary and fiscal rules under the "active/passive" criterion of Leeper (1991). First, when steady state public debt is zero, monetary and fiscal policy making reduce to two separable problems. We show that Leeper's logic extends to the share of ROTC being moderate. In contrast, with a large share of ROTC, equilibrium determinacy requires both monetary and fiscal policy to be active or both to be passive.

Second, when steady state public debt is positive, monetary policy actions generate fiscal consequences. Furthermore, fiscal policy feeds back onto the other endogenous variables of the model through wealth effects on aggregate demand that arise from the presence of ROTC. We show how these effects modify the 
interaction between monetary and fiscal policy from the scenario in which steady state public debt is equal to zero. In particular, we find that for intermediate values of steady state public debt and for both moderate and high values of the share of ROTC, the fiscal and monetary policies that ensure the determinacy of equilibrium are sensitive to the exact values of the parameters of the model.

This leads to the conclusion that it may be misleading to infer how the monetary and fiscal instruments should be used to ensure determinate equilibrium dynamics without explicit reference to the steady state level of government debt and to the share of ROTC.

\section{NOTES}

1. See for example Leith and Wren-Lewis (2000) and Schmitt-Grohe and Uribe (2007).

2. See for example Clarida et al. (1999) and Woodford (2003).

3. Note that given that all the financial assets are held by the optimizers, $V_{t+1}=(1-\lambda) V_{t+1}^{o}$. Therefore $V_{t+1}^{o}=\frac{V_{t+1}}{1-\lambda}$. The same thing holds for bonds and profits.

4. The assumption of steady state homogeneity across consumer types is present in most of the literature on ROTC; see for example Galí et al. (2007), Bilbiie (2008), Motta and Tirelli (2010), and Colciago (2011). As in Galí et al. (2007), the steady state transfer greatly simplifies the algebra but is innocuous for our results.

5. A detailed discussion of this can be found in Woodford (2003).

6. The reason we focus on this particular rule is that, as shown by Bilbiie (2008), it leads to much more clear-cut determinacy conditions.

7. In Appendix A the reader can find a detailed derivation of the log-linearized equilibrium.

8. Note that these effects of interest rate movements on financial portfolios would be irrelevant if $\lambda=0$, i.e., no ROTC.

9. The expression for $\lambda^{*}$ is different from the one presented in Bilbiie (2008). This stems from the fact that here steady state homogeneity is induced via a transfer between the two types of consumers, whereas Bilbiie (2008) obtains the same effect via a steady state fixed cost of production. However, the differences between the two approaches are quantitatively negligible.

10. We insert this paragraph before presenting the analytical results. This is because when we present the analytical results, we make use of simple numerical examples based on this parameterization.

11. In particular, we set $\eta=1$ and $\lambda=0,0.2$ and 0.35 for $\Theta>0$, whereas we fix $\eta=3, \lambda=0.35$, 0.45 , and 0.55 for $\Theta<0$.

12. In particular, we allow $\phi \in(0,4)$ and $\delta \in(-1,3)$.

13. Given a forward-looking monetary rule, the Taylor principle has an upper limit; see Woodford (2003, Ch. 4) for a detailed discussion on the upper limit of forward-looking monetary rules. This upper bound is decreasing in the share of ROTC and in the steady state level of public debt. However, for the standard parameterization, this limit is not empirically relevant, and therefore it will be ignored in what follows. For example, with $\eta=1, \lambda=0.3, \gamma=2.4$, and $\bar{\phi}=8.13$.

14. For example, with $\phi=0.8, \gamma=0$, and $\eta=3$, Assumption 2 implies $\lambda<0.89$. With $\phi=1.2$, $\gamma=2.4$ and $\eta=3$, Assumption 2 implies $\lambda<0.98$.

15. It is easy to show that adopting this proof stragety is equivalent in having just one set of conditions and then studying the bifurcation generated by the sign of $\Theta$.

16. With the benchmark parametrisation i.e. $\gamma=2.4, \eta=1$ and $\phi=0.8, \bar{\delta}=2.35$ and $\widetilde{\delta}=0.0257$. With $\gamma=3.2$ (all other parameters at their benchmark values), $\bar{\delta}=2.67$ and $\widetilde{\delta}=0.0284$. With $\phi=0.5, \bar{\delta}=2.51$ and $\widetilde{\delta}=0.029$.

17. This is formally explained in the next paragraph. 


\section{REFERENCES}

Ascari, G., A. Colciago, and L. Rossi (2011) Limited Asset Market Participation: Does it Really Matter for Monetary Policy. Bank of Finland research discussion paper 15-2011.

Barro, R. (1974) Are government bonds net wealth? Journal of Political Economy 82, 10951117.

Bernanke, B. and M. Woodford (1998) Inflation forecasts and monetary policy. Journal of Money, Credit and Banking 29, 653-685.

Bilbiie, F.O. (2008) Limited asset markets participation, monetary policy and (inverted) Keynesian logic. Journal of Economic Theory 140, 162-196.

Bilbiie, F.O. and R. Straub (2004) Fiscal Policy, Business Cycles and Labor-Market Fluctuations. MNB working paper 2004/6.

Blanchard, O. (1985) Debt, deficits, and finite horizons. Journal of Political Economy 93, 223-247.

Calvo, G.A. (1983) Staggered prices in a utility-maximizing framework. Journal of Monetary Economics $12,383-398$.

Carlstrom, T. and S. Fuerst (2005) Investment and interest rate policy: A discrete time analysis. Journal of Economic Theory 123, 4-20.

Clarida, R., J. Galí, and M. Gertler (1999) The science of monetary policy: A New Keynesian perspective. Journal of Economic Literature 37, 1661-1707.

Clarida, R., J. Galí, and M. Gertler (2000) Monetary policy rules and macroeconomic stability: Evidence and some theory. Quarterly Journal of Economics 115, 147-180.

Colciago, A. (2011) Rule of thumb consumers meet sticky wages. Journal of Money Credit and Banking 43, 325-353.

Davig, T. and E. Leeper (2006) Fluctuating macro policies and the fiscal theory. NBER Macroeconomics Annual 2006, 21, 247-316.

Di Bartolomeo, G. and L. Rossi (2007) Effectiveness of monetary policy and limited asset market participation: Neoclassical versus Keynesian effects. International Journal of Economic Theory 3, 213-218.

Felippa, C.A. and K.C. Perk (2004) Synthesis Tools for Structural Dynamics and Partitioned Analysis of Coupled Systems. Mimeo, Aerospace Engineering Sciences and Center for Aerospace Structures.

Galí, J., D. Lopez-Salido, and J. Valles (2004) Rule-of-thumb consumers and the design of interest rate rules. Journal of Money, Credit and Banking 36, 739-763.

Galí, J., D. Lopez-Salido, and J. Valles (2007) Understanding the effect of public spending on consumption. Journal of European Economic Association 5, 227-270.

Leeper, E. (1991) Equilibria under "active" and "passive" monetary and fiscal policies. Journal of Monetary Economics 27, 129-147.

Leith, C. and L. von Thadden (2008) Monetary and fiscal interactions in a New Keynesian model with capital accumulation and non-Ricardian consumers. Journal of Economic Theory 140, 279 313.

Leith, C. and S. Wren-Lewis (2000) Interactions between monetary and fiscal policy rules. Economic Journal 110, 93-108.

Linnemann, L. (2006) Interest rate policy, debt, and the indeterminacy with distortive taxation. Journal of Economic Dynamics and Control 30, 487-510.

Motta, G. and P. Tirelli (2010) Rule-of-Thumb Consumers, Consumption Habits and the Taylor Principle, University of Milano-Bicocca WP 194.

Samuelson, P. (1941) Conditions that the roots of a polynomial be less than unity in absolute value. Annals of Mathematical Statistics 12, 360-364.

Schmitt-Grohé, S. and M. Uribe (2007) Optimal simple and implementable monetary and fiscal rules. Journal of Monetary Economics 54, 1702-1725.

Taylor, J. (1993) Discretion versus policy rules in practice. Carnegie Rochester Conference Series on Public Policy 39, 195-214.

Woodford M. (2003) Interest and Prices. Princeton University Press. 


\section{APPENDIX A: USEFUL DERIVATIONS}

We impose steady state homogeneity; hence

$$
N^{r}=N^{o}=N=C^{r}=C^{o}=C=Y .
$$

The log-linearization of the ROTC budget constraint is

$$
\hat{C}_{t}^{r}=w\left(\hat{w}_{t}+\hat{N}_{t}^{r}\right)-\tilde{\tau}_{t},
$$

whereas ROTCs' and optimizers' labor supplies read as

$$
\begin{aligned}
& \hat{C}_{t}^{r}+\eta \hat{N}_{t}^{r}=\hat{w}_{t}, \\
& \hat{C}_{t}^{o}+\eta \hat{N}_{t}^{o}=\hat{w}_{t} .
\end{aligned}
$$

The log-linear optimizers' Euler equation is

$$
\hat{C}_{t}^{o}=E_{t} \hat{C}_{t}^{o}-\left\{\hat{R}_{t}-E_{t} \hat{\pi}_{t+1}\right\} .
$$

Log-linearizations of aggregate consumption and aggregate hours are

$$
\begin{aligned}
& \hat{C}_{t}=\lambda \hat{C}_{t}^{r}+(1-\lambda) \hat{C}_{t}^{o}, \\
& \hat{N}_{t}=\lambda \hat{N}_{t}^{r}+(1-\lambda) \hat{N}_{t}^{o} .
\end{aligned}
$$

Combining (A.3) and (A.3bis) with (A.5) and (A.6), we can write

$$
\hat{C}_{t}+\eta \hat{N}_{t}=\hat{w}_{t} .
$$

We plug (A.7) into (A.2) and combine it with (A.3) as

$$
\hat{C}_{t}^{r}=\left(\frac{\eta \varepsilon-\eta}{\eta \varepsilon+\varepsilon-1}\right)\left(\frac{1+\eta}{\eta}\right) \hat{C}_{t}+\left(\frac{\eta \varepsilon-\eta}{\eta \varepsilon+\varepsilon-1}\right)(1+\eta) \hat{N}_{t}-\left(\frac{\eta \varepsilon-\eta}{\eta \varepsilon+\varepsilon-1}\right) \frac{\varepsilon}{\varepsilon-1} \tilde{\tau}_{t},
$$

where, as in the main text, $\tilde{\tau}_{t}=\frac{\tau_{t}-\tau}{Y}$. Using the expression for aggregate consumption, we can write the Euler equation as

$$
\hat{C}_{t}-\lambda \hat{C}_{t}^{r}=E_{t} \hat{C}_{t+1}-\lambda E_{t} \hat{C}_{t+1}^{r}-(1-\lambda)\left\{\hat{R}_{t}-E_{t} \hat{\pi}_{t+1}\right\} .
$$

We then combine (A.8) with the latter,

$$
\begin{aligned}
& {\left[1-\lambda\left(\frac{\eta \varepsilon-\eta}{\eta \varepsilon+\varepsilon-1}\right)\left(\frac{1+\eta}{\eta}\right)\right] \hat{C}_{t} } \\
= & \left\{\begin{array}{c}
{\left[1-\lambda\left(\frac{\eta \varepsilon-\eta}{\eta \varepsilon+\varepsilon-1}\right)\left(\frac{1+\eta}{\eta}\right)\right] E_{t} \hat{C}_{t+1}-\left[\lambda\left(\frac{\eta \varepsilon-\eta}{\eta \varepsilon+\varepsilon-1}\right)(1+\eta)\right] E_{t} \Delta \hat{N}_{t+1}} \\
\quad+\left(\lambda\left(\frac{\eta \varepsilon-\eta}{\eta \varepsilon+\varepsilon-1}\right) \frac{\varepsilon}{\varepsilon-1}\right) E_{t} \Delta \tilde{\tau}_{t+1}-(1-\lambda)\left(\hat{R}_{t}-E_{t} \hat{\pi}_{t+1}\right)
\end{array}\right\},
\end{aligned}
$$


where the symbol $\Delta$ identifies the first difference operator. Given that $\hat{C}_{t}=\hat{Y}_{t}=\hat{N}_{t}$, we can rewrite (A.10) as

$$
\begin{aligned}
& {\left[1-\frac{\lambda\left(\frac{\eta \varepsilon-\eta}{\eta \varepsilon+\varepsilon-1}\right)(1+\eta)^{2}}{\eta}\right] \hat{Y}_{t}} \\
& \quad=\left\{\begin{array}{c}
{\left[1-\frac{\lambda\left(\frac{\eta \varepsilon-\eta}{\eta \varepsilon+\varepsilon-1}\right)(1+\eta)^{2}}{\eta}\right] E_{t} \hat{Y}_{t+1}} \\
+\left[\lambda\left(\frac{\eta \varepsilon-\eta}{\eta \varepsilon+\varepsilon-1}\right) \frac{\varepsilon}{\varepsilon-1}\right] E_{t} \Delta \tilde{\tau}_{t+1}-(1-\lambda)\left(\hat{R}_{t}-E_{t} \hat{\pi}_{t+1}\right)
\end{array}\right\} .
\end{aligned}
$$

Now, recalling that

$$
\Theta=(1-\lambda)\left(1-\lambda \frac{\left(\frac{\eta \varepsilon-\eta}{\eta \varepsilon+\varepsilon-1}\right)(1+\eta)^{2}}{\eta}\right)^{-1} \text { and } \Gamma=\left(\frac{\lambda}{1-\lambda}\left(\frac{\eta \varepsilon-\eta}{\eta \varepsilon+\varepsilon-1}\right) \frac{\varepsilon}{\varepsilon-1}\right)
$$

we can rewrite the Euler equation as

$$
\hat{Y}_{t}=E_{t} \hat{Y}_{t+1}-\Theta\left(\hat{R}_{t}-E_{t} \hat{\pi}_{t+1}\right)+\Theta \Gamma\left(E_{t} \widetilde{\tau}_{t+1}-\widetilde{\tau}_{t}\right)
$$

whereas on the supply side, the New Keynesian Phillips curve can be written as

$$
\hat{\pi}_{t}=\beta E_{t} \hat{\pi}_{t+1}+\kappa\left(\widehat{\mathrm{mc}}_{t}\right)
$$

where $\widehat{\mathrm{mc}}_{t}$ is the log-linear expression for the marginal costs and $\kappa=\frac{(1-\alpha)(1-\alpha \beta)}{\alpha}$. Using the fact that $\widehat{\mathrm{mc}}_{t}=\hat{w}_{t}=\hat{C}_{t}+\eta \hat{N}_{t}=(1+\eta) \hat{Y}_{t}$, we can rewrite the New Keynesian Phillips curve as

$$
\hat{\pi}_{t}=\beta E_{t} \hat{\pi}_{t+1}+\sigma \hat{Y}_{t}
$$

where $\sigma=(1+\eta) \kappa$.

The government has a log-linearized budget constraint of the type

$$
\beta\left(\widetilde{b}_{t+1}-\gamma \hat{R}_{t}\right)+\widetilde{\tau}_{t}=\left(\widetilde{b}_{t}-\gamma \hat{\pi}_{t}\right)
$$

where, as in the main text, $\widetilde{b}_{t}=\frac{b_{t}-b}{Y}$ and $\gamma=\frac{b}{Y}$. Furthermore, we plug the tax rule and the monetary rule into the Euler equation and the government budget constraint as

$$
\begin{gathered}
\hat{Y}_{t}=E_{t} \hat{Y}_{t+1}-\Theta(\phi-1) E_{t} \hat{\pi}_{t+1}+\Theta \Gamma \delta\left(E_{t} \widetilde{b}_{t+1}-\widetilde{b}_{t}\right), \\
\beta\left(\widetilde{b}_{t+1}-\gamma \phi E_{t} \hat{\pi}_{t+1}\right)=(1-\delta) \widetilde{b}_{t}-\gamma \hat{\pi}_{t} .
\end{gathered}
$$

With these two last equations, together with the New Keynesian Phillips curve of (A.14), we construct the system of three equations we use for the determinacy analysis. 


\section{APPENDIX B: DETERMINACY ANALYSIS OF THE $3 \times 3$ SYSTEM}

\section{B.1. HURWITZ POLYNOMIAL}

To derive the main results of the paper analytically, we adopt the technique of transforming the polynomial obtained from the characteristic equation-see Samuelson (1941) and more recently, Felippa and Park (2004, Section 4, p. 18) and Ascari et al. (2011). Given the characteristic polynomial

$$
\mathcal{P}_{A}(\mu) \equiv \mu^{n}+\mathcal{A}_{n-1} \mu^{n-1}+\ldots+\mathcal{A}_{n-(n-1)} \mu+\mathcal{A}_{0},
$$

the stability properties would depend on the location of the roots inside the unit circle in the complex $\mu$ plane, i.e., $\left|\mu_{i}\right|<1$. It is in general possible to transform this polynomial into a Hurwitz polynomial $\mathcal{P}_{H}(\psi)$, whose stability properties depend on the location of the roots in the left-hand plane $\mathbf{R}(\psi)<0$. To pass from $\mathcal{P}_{A}(\mu)$ to $\mathcal{P}_{H}(\psi)$, one can use the conformal involuntary transformation

$$
\mu=\frac{1+\psi}{1-\psi} .
$$

Given B.2, we have $|\mu| \lessgtr 1 \Longleftrightarrow \psi \lessgtr 0$.

For the exercise presented in this paper, the third-order characteristic polynomial can be transformed into the Hurwitz polynomial using $\mu=\frac{1+\psi}{1-\psi}$ :

$$
\hat{\mathcal{P}}_{H}(\psi)=\frac{(1+\psi)^{3}}{(1-\psi)^{3}}+\mathcal{A}_{2} \frac{(1+\psi)^{2}}{(1-\psi)^{2}}+\mathcal{A}_{1} \frac{1+\psi}{1-\psi}+\mathcal{A}_{0} .
$$

Hence, once we expand the polynomial we obtain a quotient of two polynomials; $\hat{\mathcal{P}}_{H}(\psi)=P_{H}(\psi) / Q_{H}(\psi)$ where the roots of $\hat{\mathcal{P}}_{H}(\psi)$ are the roots of $\mathcal{P}_{H}(\psi)$. We then need to study the stability of the following polynomial

$$
\mathcal{P}_{H}(\psi)=\psi^{3}+\mathcal{B}_{2} \psi^{2}+\mathcal{B}_{1} \psi+\mathcal{B}_{0},
$$

where $\mathcal{B}_{0}=\frac{1+\mathcal{A}_{2}+\mathcal{A}_{1}+\mathcal{A}_{0}}{1-\mathcal{A}_{2}+\mathcal{A}_{1}-\mathcal{A}_{0}}, \mathcal{B}_{1}=\frac{3+\mathcal{A}_{2}-\mathcal{A}_{1}-3 \mathcal{A}_{0}}{1-\mathcal{A}_{2}+\mathcal{A}_{1}-\mathcal{A}_{0}}$, and $\mathcal{B}_{2}=\frac{3-\mathcal{A}_{2}-\mathcal{A}_{1}+3 \mathcal{A}_{0}}{1-\mathcal{A}_{2}+\mathcal{A}_{1}-\mathcal{A}_{0}}$.

\section{B.2. PROOF OF PROPOSITIONS 1 AND 2}

The dynamic system in matrix formulation can be written as

$$
\left[\begin{array}{c}
E_{t} \hat{Y}_{t+1} \\
E_{t} \hat{\pi}_{t+1} \\
\widetilde{b}_{t+1}
\end{array}\right]=J\left[\begin{array}{c}
\hat{Y}_{t} \\
\hat{\pi}_{t} \\
\widetilde{b}_{t}
\end{array}\right]
$$

with

$$
J=\left[\begin{array}{ccc}
\frac{\sigma}{\beta}(\Theta-\Theta \phi+\gamma \delta \phi \Gamma \Theta)+1 & \frac{1}{\beta} \gamma \delta \Gamma \Theta-\frac{1}{\beta}(\Theta-\Theta \phi+\gamma \delta \phi \Gamma \Theta) & \delta \Gamma \Theta+\frac{1}{\beta} \delta \Gamma \Theta(\delta-1) \\
-\frac{\sigma}{\beta} & \frac{1}{\beta} & 0 \\
-\frac{\sigma}{\beta} \gamma \phi & \frac{1}{\beta} \gamma \phi-\frac{1}{\beta} \gamma & -\frac{1}{\beta}(\delta-1)
\end{array}\right] .
$$


The coefficients of the characteristic polynomia, as in (B.1), are

$$
\begin{gathered}
\mathcal{A}_{0}=-\mu_{1} \mu_{2} \mu_{3}=-\operatorname{det}(J)=-\left(\frac{1-\delta}{\beta^{2}}+\frac{\Gamma \Theta \sigma \gamma \delta}{\beta^{2}}\right), \\
\mathcal{A}_{1}=\mu_{1} \mu_{2}+\mu_{2} \mu_{3}+\mu_{1} \mu_{3}=\frac{\beta+(1-\delta)[1+\beta+\Theta \sigma(1-\phi)]+\Theta \sigma \gamma \Gamma \delta(1+\beta \phi)}{\beta^{2}},
\end{gathered}
$$

$$
\mathcal{A}_{2}=-\left(\mu_{1}+\mu_{2}+\mu_{3}\right)=-\operatorname{trace}(J)=-\frac{\beta+1+(1-\delta)+\sigma \Theta[1-\phi(1-\gamma \delta \Gamma)]}{\beta} .
$$

Applying the conformal transformation to get the Hurwitz polynomial yields

$$
\begin{gathered}
\mathcal{B}_{0}=\frac{(1-\phi) \Theta \sigma(1-\beta-\delta)}{(1+\beta-\delta)[2(1+\beta)+(1-\phi) \Theta \sigma]+2 \Theta \sigma \gamma \Gamma \delta(1+\beta \phi)}=-\left(\psi_{1} \psi_{2} \psi_{3}\right), \\
\mathcal{B}_{1}=\frac{\Theta \sigma(1-\phi)[\delta(1+2 \Gamma \gamma)-1-\beta]+2(\beta-1)((\beta-1)+\delta)}{(1+\beta-\delta)[2(1+\beta)+(1-\phi) \Theta \sigma]+2 \Theta \sigma \gamma \Gamma \delta(1+\beta \phi)}=\psi_{1} \psi_{2}+\psi_{2} \psi_{3}+\psi_{3} \psi_{1}, \\
\mathcal{B}_{2}=\frac{(1-\phi) \sigma \Theta(\beta-1+\delta)+4\left[\beta^{2}-1+\delta(\Gamma \Theta \sigma \gamma-1)\right]}{(1+\beta-\delta)[2(1+\beta)+(1-\phi) \Theta \sigma]+2 \Theta \sigma \gamma \Gamma \delta(1+\beta \phi)}=-\left(\psi_{1}+\psi_{2}+\psi_{3}\right) .
\end{gathered}
$$

For the rational expectation equilibrium (REE) to be unique, the polynomial $\mathcal{P}_{H}(\psi)$ must display exactly one negative root. It follows that we need $\mathcal{B}_{0}$ to be positive and at least one at $\mathcal{B}_{1}$ and $\mathcal{B}_{2}$ to be negative. The first condition implies that $\mathcal{P}_{H}(\psi)$ has either one or three negative roots. When $\mathcal{B}_{0}>0$, the second condition implies, by Decartes' rule of sign, that $\mathcal{P}_{H}(\psi)$ has either two or zero positive roots. However, when $\mathcal{B}_{0}>0$ and either $\mathcal{B}_{1}$ or $\mathcal{B}_{2}$ (or both) are negative, $\mathcal{P}_{H}(-\psi)$ displays only one sign change; hence $\mathcal{P}_{H}(\psi)$ has exactly one negative root.

Proof strategy: we study the sign of $\mathcal{B}_{0}$ in the policy space $\phi-\delta$, and we restrict the study of the sign of $\mathcal{B}_{1}$ and $\mathcal{B}_{2}$ to the policy space where $\mathcal{B}_{0}$ is positive. We separately consider the cases where $\Theta>0$ and $\Theta<0 .{ }^{15}$

Case $\Theta>0$.

Assumption 1. $\gamma<\frac{1}{\Gamma \sigma}$ (see main text for a discussion about this assumption).

In this case the numerator of $\mathcal{B}_{0}$, is positive iff

$$
[\phi>1 \cap \delta>(1-\beta)] \cup[\phi<1 \cap \delta<(1-\delta)],
$$

whereas the denominator of $\mathcal{B}_{0}$ is positive iff

$$
[\phi \in(0, \bar{\phi}) \cap \delta<(\bar{\delta})] \cup[\phi \notin(0, \bar{\phi}) \cap \delta>(\bar{\delta})]
$$

where $\bar{\phi}=\frac{2(1+\beta)+\Theta \sigma-2 \gamma \Gamma \Theta \sigma}{\Theta \sigma+2 \beta \gamma \Gamma \Theta \sigma}$ and $\bar{\delta}=\frac{-2(1+\beta)^{2}-\Theta \sigma((1+\beta)(1-\phi))}{-2(1+\beta)-\Theta \sigma(1-\phi-2 \gamma \Gamma(1+\beta \phi))}$. Note that if Assumption 1 holds, then $\bar{\phi}>1$. Hence $\mathcal{B}_{0}>0$ iff

$$
[\phi \in(1, \bar{\phi}) \cap \delta \in(1-\beta, \bar{\delta})] \cup[\phi \notin(1, \bar{\phi}) \cap \delta \notin(1-\beta, \bar{\delta})] .
$$


Note that if $\lambda$ or $\gamma$ equals zero, then $\bar{\delta}=1+\beta$ and $\bar{\phi}=1+\frac{2(1+\beta)}{\Theta \sigma}$. Next we study the sign of $\mathcal{B}_{2}$. For $\phi>1$ and $\delta>1-\beta$, the numerator of $\mathcal{B}_{2}$ is always negative. On the other hand, if $\phi<1$, the numerator of $\mathcal{B}_{2}$ is negative iff

$$
\delta \notin(1-\beta, \widetilde{\delta}),
$$

where $\widetilde{\delta}=\frac{-\Theta \sigma(1-\beta)(1-\phi)+4(1-\beta)(1+\beta)}{4-\Theta \sigma(1-\phi+4 \gamma \Gamma)}$. Hence, it follows that $\mathcal{B}_{2}<0$ if

$$
\begin{aligned}
& {[\phi \in(1, \bar{\phi}) \cap \delta \in(1-\beta, \bar{\delta})]} \\
& \cup[\phi>(\bar{\phi}) \cap \delta>\bar{\delta}] \\
& \cup[\phi<1 \cap \delta \notin(1-\beta, \widetilde{\delta})] .
\end{aligned}
$$

Note that for standard parameterization, $\bar{\delta}>\widetilde{\delta}$ if $\phi<1 .{ }^{16}$ Therefore the necessary and sufficient condition for REE is

$$
[\phi \in(1, \bar{\phi}) \cap \delta \in(1-\beta, \bar{\delta})] \cup[\phi \notin(1, \bar{\phi}) \cap \delta \notin(1-\beta, \bar{\delta})]
$$

Case $\Theta<0$.

Assumption 2. $\Theta \leq \frac{-2+2 \beta}{2 \gamma \sigma+\sigma \phi+2 \gamma \sigma \phi}$ (see main text for a discussion about this assumption).

The numerator of $\mathcal{B}_{0}>0$ iff

$$
[\phi \in(\max (0, \bar{\phi}), 1) \cap \delta>(1-\beta)] \cup[\phi>1 \cap \delta<(1-\beta)],
$$

whereas the denominator of $\mathcal{B}_{0}>0$ iff

$$
[\phi>0 \cap \delta<\bar{\delta}] .
$$

Note that $\bar{\delta} \in(1-\beta, 1+\beta) .{ }^{17}$

Hence $\mathcal{B}_{0}>0$ iff

$$
\begin{aligned}
& \{\phi \in[\max (0, \bar{\phi}), 1] \cap \delta \in(1-\beta, \bar{\delta})\} \\
& \cup[\phi>1 \cap \delta \notin(1-\delta, \bar{\delta})] .
\end{aligned}
$$

We now focus on the study of the sign of $\mathcal{B}_{2}$. It is easy to show that the numerator of $\mathcal{B}_{2}$ is positive iff

$$
[\phi<1 \cap \delta<\tilde{\delta}] \cup[\phi>1 \cap \delta>\widetilde{\delta}] .
$$

It follows that $\mathcal{B}_{2}<0$ iff

$$
[\phi>1 \cap \delta \notin(\widetilde{\delta}, \bar{\delta})] \cup[\phi<1 \cap \delta \in(\widetilde{\delta}, \bar{\delta})]
$$

where $\widetilde{\delta}<(1-\beta)<\bar{\delta}$. Hence, when $\phi>1 \cap \delta \in(\widetilde{\delta}, 1-\beta)$, both $\mathcal{B}_{0}$ and $\mathcal{B}_{2}$ are positive. Therefore, for Decartes' rule of signs, two positive roots require $\mathcal{B}_{1}<0$ in the policy space $[\phi>1 \cap \delta \in(\widetilde{\delta}, 1-\beta)]$. It is easy to show that in this policy space the denominator of $\mathcal{B}_{1}$ is positive, whereas its numerator is negative. Therefore, when $[\phi>1 \cap \delta<1-\beta]$, the system is determinate. 
To conclude, when $\Theta<0$ the system is determinate iff

$$
[\phi(\max (0, \bar{\phi}), 1) \cap \delta \in(1-\beta, \bar{\delta})] \cup[\phi>1 \cap \delta \notin(1-\delta, \bar{\delta})]
$$

\section{The derivatives of $\bar{\delta}$}

Q.E.D.

Here we study the sign of

$$
\begin{aligned}
& \frac{\partial \bar{\delta}}{\partial \lambda}=\frac{\partial \bar{\delta}}{\partial \Theta} \frac{\partial \Theta}{\partial \lambda} \\
& =\left\{\left[\begin{array}{c}
-\sigma[1-\phi-2 \gamma \Gamma(1+2 \beta \gamma \Gamma)] \\
{\left[2(1+\beta)^{2}+\Theta \sigma(1+\beta)(1-\phi)\right]} \\
-\sigma(1+\beta)(1-\phi)\left(\begin{array}{c}
-2 \beta-\sigma \Theta \\
+2 \gamma \Gamma \Theta \sigma+\Theta \sigma \phi+2 \beta \gamma \Gamma \Theta \sigma \phi
\end{array}\right] \\
(-2-2 \beta-\sigma \Theta+2 \gamma \Gamma \Theta \sigma+\Theta \sigma \phi+2 \beta \gamma \Gamma \Theta \sigma \phi)^{2}
\end{array}\right\}\left(\frac{\partial \Theta}{\partial \lambda}\right),\right. \\
& \frac{\partial \bar{\delta}}{\partial \phi}=\left\{\frac{\left[\begin{array}{c}
\Theta \sigma(1+2 \beta \gamma \Gamma)\left[2(1+\beta)^{2}+\Theta \sigma(1+\beta)(1-\phi)\right] \\
+\Theta \sigma(1+\beta)(-2-2 \beta-\Theta \sigma+2 \gamma \Gamma \Theta \sigma+\Theta \sigma \phi+2 \beta \gamma \Gamma \Theta \sigma \phi)
\end{array}\right]}{(-2-2 \beta-\Theta \sigma+2 \gamma \Gamma \Theta \sigma+\Theta \sigma \phi+2 \beta \gamma \Gamma \Theta \sigma \phi)^{2}}\right\} \\
& \frac{\partial \bar{\delta}}{\partial \gamma}=\left[\frac{\left[2(1+\beta)^{2}+\Theta \sigma(1+\beta)(1-\phi)\right] 2 \Gamma \Theta \sigma(1+\phi \beta)}{(-2-2 \beta-\Theta \sigma+2 \gamma \Gamma \Theta \sigma+\Theta \sigma \phi+2 \beta \gamma \Gamma \Theta \sigma \phi)^{2}}\right] \text {. }
\end{aligned}
$$

The sign of $\frac{\partial \bar{\delta}}{\partial \lambda}: \frac{\partial \Theta}{\partial \lambda}$ is always positive for $\lambda \neq \frac{\eta}{\varphi(1+\eta)^{2}}$.

Furthermore,

$$
\frac{\left[\begin{array}{c}
-\sigma[1-\phi-2 \gamma \Gamma(1+2 \beta \gamma \Gamma)]\left[2(1+\beta)^{2}+\Theta \sigma(1+\beta)(1-\phi)\right] \\
-\sigma(1+\beta)(1-\phi)(-2-2 \beta-\sigma \Theta+2 \gamma \Gamma \Theta \sigma+\Theta \sigma \phi+2 \beta \gamma \Gamma \Theta \sigma \phi)
\end{array}\right]}{(-2-2 \beta-\sigma \Theta+2 \gamma \Gamma \Theta \sigma+\Theta \sigma \phi+2 \beta \gamma \Gamma \Theta \sigma \phi)^{2}}>0
$$

regardless of the sign of $\Theta$.

The numerator of $\frac{\partial \bar{\delta}}{\partial \phi}$ is positive if $\Theta>0 \cap \phi \in(0, \bar{\phi})$, and negative if $\Theta<0 \cap$ $\phi \in(0, \bar{\phi})$, whereas the denominator is always positive.

The numerator of $\frac{\partial \bar{\delta}}{\partial \gamma}$ is positive iff $\Theta>0 \cap \phi>0$, and negative if $\Theta<0 \cap \phi>0$, whereas the denominator is always positive.

Ultimately, when $\Theta>0$, the derivatives of $\bar{\delta}$ with respect to $\gamma, \lambda$, and $\phi$ are positive and if either $\lambda$ or $\gamma$ equals zero, then $\bar{\delta}=1+\beta$. Hence if $\Theta>0, \bar{\delta}$ is bounded below by $1+\beta$. On the other hand, when $\Theta<0, \bar{\delta}$ is decreasing in $\gamma$ and $\phi$ and increasing in $\lambda$. Note that $\frac{\partial \bar{\delta}}{\partial \lambda}>0$ and as $\lambda \rightarrow 1$ and/or $\gamma=0, \bar{\delta}=1+\beta$. Hence if $\Theta<0, \bar{\delta}$ is bounded above by $1+\beta$. 